\title{
PENINGKATAKAN KEMAMPUAN PENELITIAN TINDAKAN \\ KELAS BAGI GURU PENDIDIKAN AGAMA ISLAM PADA SEKOLAH MENENGAH PERTAMA DAN MADRASAH TSANAWIYAH MUHAMMADIYAH SE KULON PROGO
}

\author{
Sutipyo R'iya ${ }^{1}$, Hanif Cahyo Adi Kistoro ${ }^{2}$ \\ ${ }^{1}$ Prodi PAI Universitas Ahmad Dahlan Yogyakarta \\ sutipyo@pai.uad.ac.id \\ ${ }^{2}$ Prodi PAI Universitas Ahmad Dahlan Yogyakarta \\ hanif.kistoro@pai.uad.ac.id
}

\begin{abstract}
ABSTRAK
Latar Belakang: Penelitian merupakan hal yang sangat penting dalam dunia pendidikan, dengan penelitian banyak permasalahan yang dapat diselesaikan secara ilmiah. Penelitian Tidakan Kelas (PTK) merupakan salah satu jenis penelitian yang dilakukan oleh guru berdasarkan permasalahan riil yang dihadapi. Pelaksanaan Penelitian Tindakan Kelas (PTK) terutama oleh guru-guru Pendidikan Agama Islam di Sekolah Menengah Pertama (SMP) dan Madrasah Tsanawiyah (MTs) Muhammadiyah di Kulon Progo masih sangat minim.

Tujuan: Meningkatkan kemampuan Penelitian Tindakan Kelas bagi guru-guru Pendidikan Agama Islam di SMP dan MTs Muhammadiyah se Kulon Progo dengan indikator dapat menyusun proposal PTK.

Metode: Pertemuan dengan guru-guru Pendidikan Agama Islam, melakukan pelatihan Penelitian Tindakan Kelas (PTK) dengan menyampaikan metodologi penelitian, penugasan penyusunan proposal PTK, dan bedah proposal.

Hasil: Peningkatan pengetahuan teoritik Penelitian Tindakan Kelas, dari 25 peserta dengan menyatakan puas dengan pelatihan yang dilaksanakan. Dalam satu bulan dari keseluruhan peserta pelatihan $40 \%$ berhasil menyusun proposal PTK. Proposal tersebut, dibedah dan disempurnakan dengan bimbingan para pendamping.
\end{abstract}

Kata kunci: Penelitian Tindakan Kelas, guru Pendidian Agama Islam

\begin{abstract}
Background: Research is fundamental in the world of education, with research, many problems that can be solved scientifically. Classroom Action Research (CAR) is one type of study conducted by teachers based on the real issues faced. The implementation of Classroom Action Research (CAR), especially by Islamic Religious Education teachers in the Middle School (SMP) and Madrasah Tsanawiyah (MTs) Muhammadiyah in Kulon Progo is still very minimal.

Objective: To increase the ability of Classroom Action Research for Islamic Religious Education teachers in Muhammadiyah Junior High Schools and MTs in Kulon Progo with indicators to compile CAR proposals.

Methods: Meeting of Islamic Religious Education teachers, conducting Classroom Action Research (CAR) training by presenting the research methodology, assigning the preparation of CAR proposals, and reviewing proposals.

Results: Increased theoretical knowledge of Classroom Action Research, from 25 participants who expressed satisfaction with the training. Within one month, $40 \%$ of the trainees successfully compiled a CAR proposal. The proposal, dissected and perfected with the guidance of the assistants.
\end{abstract}

Jurnal Pengabdian Masyarakat Karya Husada/Vol.1, No. 2 Tahun 2019 
Keywords: Classroom Action Research, Islamic Religious Education teacher

\section{PENDAHULUAN}

Permasalahan-permasalahan di dunia pendidikan selalu dinamis dan berkembang sesuai dengan perkembangan zaman. Hanya sekolah yang adaptif dan dapat menyesuaikan dengan perkembangan zaman yang akan eksis dan mendapat tanggapan baik dari masyarakat. Pendidikan saat ini tantangannya sangat besar, sehingga harus mendapat perhatian dari seluruh civitas akademika. Guru sebagai bagian dari civitas akademika, mempunyai peranan dan tanggung jawab besar terhadap maju dan mundurnya suatu sekolah.

Di lingkungan Majelis Pendidikan Dasar dan Menengah Pimpinan Daerah Kulon Progo, terdapat 17 Sekolah Menengah Pertama dan 3 Madrasah Tsanawiyah. Perkembangan amal usaha ini ada yang berkembang baik dan ada juga yang mengalami kondisi kurang baik, mulai dari jumlah siswa dan juga prestasi siswanya.

Permasalahan sekolah satu dengan yang lain sangat beragam, misalnya mengapa motivasi belajar siswa rendah dan prestasi belajar siswa rendah.
Sementara di sekolah lain mengalami perkembangan akhlak siswa yang urang baik. Dalam satu sekolah kadangkadang mempunyai masalah yang komplek dan beragam,sehingga sulit untuk diurai dari mana akan dimulai untuk dicari penyelesaiannya.

Kondisi yang demikian ini, menjadi keprihatinan seluruh insan yang berkecimpung di dalamnya sehingga perlu penanganan sesegera mungkin. Untuk memperoleh jawaban yang jelas dan dapat dipertanggung jawabkan secara ilmiah, maka seluruh masalah itu harus diselidiki secara seksama. Penyelidikan ilmiah atau dikenal dengan penelitian ilmiah mempunyai ragam yang sangat banyak. Penelitian Tindakan kelas merupakan salah satu dari bentuk penelitian untuk mengatasi permasalahan-permasalahan pendidikan.

Salah satu masalah yang menjadi masalah umum adalah masalah prestasi belajar siswa. Untuk meningkatkan prestasi siswa tentunya perlu dilakukan evaluasi secara menyeluruh, mulai dari input siswa, proses pembelajaran, maupun fasilitas sekolah (Suryosubroto, 
2008). Berkait dengan input siswa, setiap sekolah sangat beraragam, lebihlebih dengan penerapan sistem zonasi pada penerimaan siswa baru. Oleh karena itu, sekolah sudah saatnya dapat memetakan input siswa, karena siswa yang masuk ke suatu sekolah karakter dan kemampuannya sangat beragam. Keberagaman input dari siswa ini, tentu berdampak pada pengelolaan kelas yang berbeda, sehingga penanganan anak juga harus berbeda. Sebagaimana disampaikan Hamzah Uno (2011) bahwa pada hakikatnya pembelajaran itu adalah bersifat individual.

Sementara itu, fasilitas yang dimiliki oleh sekolah dan madrasah juga sangat beragam, walaupun secara garis besar sudah cukup layak. Artinya segala kebutuhan untuk proses pembelajaran sudah tercukupi, walaupun pada beberapa sekolah dan madrasah masih sangat sederhana. Oleh karena itu, untuk meningkatkan prestasi belajar siswa diperlukan evaluasi terhadap proses pembelajaran yang dilakukan oleh semua guru dari madrasah. Apakah guru sudah mengajar sesuai dengan tipe siswa di setiap kelas atau tidak. Pengajaran yang berbasis kebutuhan kelas dapat dilakukan setelah guru dapat memahami karakteristik kelas yang diawali oleh pemahaman karakter kelas. Pemahaman karakter kelas inilah merupakan awal dari sebuah Penelitian Tindakan Kelas (Arikunto dkk, 2009).

Arikunto (2009) mengatakan bahwa dengan Penelitian Tindakan Kelas maka pengajaran tidak hanya dilakukan di dalam kelas, karena pengajaran disesuaikan dengan keadaan dan karakteriktik kelas. Pencermatan terhadap kegiatan pendidikan yang dilakukan secara sengaja untuk merubah perilaku belajar siswa maka menjadi sangat penting untuk keberhasilan pembelajaran. Proses inilah merupakan tahap demi tahap yang harus dilalalui oleh Penelitian Tindakan Kelas.

Demikianlah bahwa Peneitian Tindakan kelas merupakan sesuatu yang sangat penting. Akan tetapi guru-guru Pendidikan Agama Islam di Sekolah Menengah Pertama dan di Madrasah Tsanawiyah Muhammadiyah se Kulon Progo masih sangat minim pelakukan PTK. Oleh karena itu, pelatihan yang akan dilaksanakan ini bertujuan untuk memberikan pengetahuan tentang proses pelaksanaan Penelitian Tindakan kelas yang menjadi kewajiban seorang guru untuk mencari solusi dari setiap permalasahan yang terjadi pada setiap kelas. Dengan Penelitian Tindakan 
kelas, diharapkan setiap guru dapat mengajar secara maksimal dan sesuai dengan karakteristik kelas, sehingga hasil yang diperoleh dari setiap Sekolah Menengah Pertama dan Madrasah Tsanawiyah ini menjadi semakin baik dan meningkat.

\section{Permasalahan dan Solusi yang di tawarkan.}

Upaya untuk memperbaiki proses pembelajaran yang tersistem, terancana dan terukur, maka dirasa sangat perlu agar setiap guru dapat melakukan penelitian tindakan kelas, sehingga para guru dapat memperbaiki proses pembelajaran yang di sesuaikan dengan karakter anak. Secara garis besar permasalahan mitra meliputi:

1. Minimnya pengetahuan Penelitian Tindakan Kelas bagi guru Pendidikan Agama Islam di

Sekolah Menengah Pertama dan Madrasah Tsanawiyah

Muhammadiyah se Kulon Progo.

2. Minimnya keterampilan Penelitian Tindakan Kelas bagi guru Pendidikan Agama Islam di Sekolah Menengah Pertama dan Madrasah Tsanawiyah se Kulon Progo.

Untuk mengetasi dua masalah di atas solusi yang ditawarkan adalah:
1. Peningkatan Pemahaman PTK

$$
\text { Pemahaman terhadap }
$$

permasalahan kelas harus dimiliki dan dijiwai oleh semua guru, sehingga guru harus melakukan introspeksi diri terhadap proses pembelajaran. Mengapa nilai yang diperoleh siswa dari mata pelajaran yang diampu tidak/kurang baik. Ada beberapa sebab yang memungkinkan rendahnya prestasi yang diraih siswa, motivasi belajar rendah, strategi pembelajaraan tidak menarik, materi yang disampaikan tidak/kurang jelas atau sebab-sebab yang lain (Hamalik, 2012). Apabila permasalahanpermasalahan yang ada pada proses pembelajaran ini disadari oleh pra guru lalu dilakukan perubahan, secara sungguh-sungguh dan tersistem dengan baik maka, hasil pembelajaran akan maksimal.

Untuk meningkatkan pemahaman ini maka akan dilakukan workshop tentang pentingnya penelitian Tindakan Kelas (PTK) yang meliputi materi, bagaimana mengindentifikas permasalahan kelas, menentukan masalah yang layak dijadikan PTK 
dan bagaimana proses penyusunan PTK.

2. Pelatihan Penyusunan Usulan dan Pelaksanaan PTK

Pelatihan ini adakan dilakukan untuk mengajak guru melakukan introspeksi dan evaluas diri terhadap proses pembelajaran yang selama ini dilakukan. Para guru akan dipandu mencari permasalahan yang terjadi dalam pelaksanaan pembelajaran. Setelah diketahui problem yang terjadi di kelas akan dicarikan solusi pemecahannya, untuk dilakukan perlakuan terhadap kelas tersebut. Melalui pelatihan ini, diharapkan:

a) Memberikan pemahaman kepada para guru akan pentingnya Penelitian Tindakan Kelas.

b) Memberikan pemahahan dan keterampilan dalam melakukan perlakukan pada proses Penelitian Tindakan Kelas

Setiap guru peserta dapat melakukan Penelitian Tindakan Kelas.

\section{METODE}

Pelatihan Penelitian Tindakan Kelas bagi guru-guru Madrasah Tsanawiyah Muhammadiyah se kulon
Progo direncanakan secara terstruktur dan terorganisasi melalui pelatihan. Materi pelatihan diantaranya adalah perencanaan materi, penyusunan modul pelatihan, media dan evaluasi. Materi akan dikemas sedemikian rupa dalam bentuk modul pelatihan atau power point.

Adapun metode pelatihan akan digunakan beberapa metode, diantaranya:

1. Ceramah dan diskusi, diberikan pengantar dan arahan agar peserta memahami gambaran pelatihan dan target capaian;

2. Pemberian materi, diupayakan agar pelatihan menjadi lebih efektif dan efisien karena peserta akan lebih mudah dalam menerima dan memahai materi yang diberikan.

3. Diskusi dan pemberian contoh kasus, sehingga diharapkan peserta akan lebih memahami materi.

4. Praktik penyusunan proposal penelitian tindakan kelas.

5. Evaluasi, Dilakukan evaluasi hasil pelatian.

6. Rencana Tindak Lanjut (RTL), dilakukan agar adanya pendampingan dalam hal perumusan materi dan membuatan media serta alat evaluasi. 


\section{HASIL DAN PEMBAHASAN}

\section{HASIL}

Pelatihan Penelitian Tindakan Kelas ini untuk guru Pendidikan Agama Islam pada Sekolah Menengah Pertama dan Madrasah Tsanawiyah (MTs) Muhammadiyah se Kulonprogo. Setelah dilakukan koordinasi dengan Majelis Dikdasmen Pengurus Daerah Muhammadiyah Kulon Progo kemudian dilakukan koordinasi dengan kepala sekolah SMP dan MTs Muhammadiyah se Kulon Progo. Jumlah peserta direncanakan sebanyak 29 orang, akan tetapi yang hadir pada saat pelatihan sebanyak 26 orang.

Tabel 1. Asal sekolah peserta pelatihan

\begin{tabular}{|c|l|c|}
\hline No & \multicolumn{1}{|c|}{ Asal Sekolah } & Jumlah \\
\hline 1 & $\begin{array}{l}\text { Sekolah Menengah } \\
\text { Pertama } \\
\text { Muhammadiyah }\end{array}$ & 21 \\
\hline 2 & $\begin{array}{l}\text { Madrasah Tsanawiyah } \\
\text { Muhammadiyah }\end{array}$ & 5 \\
\hline \multicolumn{2}{|c|}{ Total } & 26 \\
\hline
\end{tabular}

Jumlah peserta yang berasal dari

Sekolah Menengah Pertama

Muhammadiyah sebanyak 21 orang dan yang berasal dari Madrasah Tsanawiyah Muhammadiyah sebanyak 5 orang.
Perbandingan jumlah peserta laki-laki dan perempuan adalah 15 orang dan peserta laki-laki sebanyak 11 orang.

Tabel 2. Peserta pelatihan dilihat dari jenis kelamin

\begin{tabular}{|c|l|c|}
\hline No & \multicolumn{1}{|c|}{ Asal Sekolah } & Jumlah \\
\hline 1 & Laki-laki & 11 \\
\hline 2 & Perempuan & 15 \\
\hline \multicolumn{2}{|r|}{ Total } & 26 \\
\hline
\end{tabular}

Pelaksanaan Pelatihan Penelitian Tindakan Kelas ini pada tanggal 3 Agustus 2019 bertempat di Kampus 6 Universitas Ahmad Dahlan yang berlokasi di Wates Kulon Progo. Penyampaian materi oleh Sutipyo Ru'iya S.Ag., M.Si.; Hanif Cahyo Adi Kistoro, S.Ag., MA.; dan Asih Suprapti, S.Pd.I.

Pada pertemuan pertama disampaikan dua materi sebagai berikut:

Tabel 3. Time schedule pelatihan PTK

\begin{tabular}{|c|l|l|}
\hline No. & \multicolumn{1}{|c|}{ Acara } & \multicolumn{1}{|c|}{$\begin{array}{c}\text { Nara } \\
\text { Sumber }\end{array}$} \\
\hline 1 & $\begin{array}{l}\text { Materi 1: } \\
\text { Mengapa Guru PAI } \\
\text { Harus Melakukan } \\
\text { PTK }\end{array}$ & $\begin{array}{l}\text { Sutipyo } \\
\text { Ru'iya, } \\
\text { S.Ag., M.Si. }\end{array}$ \\
\hline 2 & Materi 2: Step by & Hanif \\
\hline
\end{tabular}




\begin{tabular}{|c|l|l|}
\hline & $\begin{array}{l}\text { Step Perencanaan } \\
\text { dan Pelaksanaan } \\
\text { PTK }\end{array}$ & $\begin{array}{l}\text { Cahyo AK., } \\
\text { S.Ag., MA. }\end{array}$ \\
\hline 3 & $\begin{array}{l}\text { Materi 3: Penulisan } \\
\text { literasi karya ilimiah } \\
\text { dengan } \\
\text { menggunakan } \\
\text { aplikasi Zotero }\end{array}$ & $\begin{array}{l}\text { Sutipyo } \\
\text { Ru'iya, } \\
\text { S.Ag., M.Si. }\end{array}$ \\
\hline 4 & $\begin{array}{l}\text { Materi 4: Sharing } \\
\text { dan Kiat Meraih } \\
\text { Hibah PTK }\end{array}$ & $\begin{array}{l}\text { Asih } \\
\text { Suprapti, } \\
\text { S.Pd. }\end{array}$ \\
\hline
\end{tabular}

Setelah materi disampaikan, selanjutnya peserta ditugaskan untuk menyusun proposal PTK selama satu bulan.

1. Pembahasan
a) Meningkatkan
motivasi melakukan PTK
Motivasi sangat penting bagi seseorang untuk melakukan sesuatu, karena motivasi merupakan penggerak bagi orang tersebut untuk mrlakukan sesuatu. Abraham Maslow mengatakan bahwa motivasi bisa tumbuh jika seseorang mempunyai kebutuhan (Uno, 2012). Sementara itu, Bagus Riyono mengatakan bahwa motivasi seorang dapat tubuh jika orang tersebut dapat mengindentifikasi resiko yang akan

dihadapi di masa akan datang sehingga dia dapat menghitung seberapa besar ketidakpastian yang akan dihadapi bagi dirinya (Riyono, 2014).

Motivasi untuk melakukan PTK bagi guru SMP Muhammadiyah dan MTs Muhammadiyah di Kulon Progo tergolong lemah. Hal ii diungkapkan oleh Agus Wardoyo yang mengakatan bahwa "Masih ada beberapa guru SMP yang mengatakan belum perlu untuk melakukan PTK" (Wawancara langsung). Oleh karena itu, untuk membangkitkan motivasi para guru, pada materi pertama di sampaikan mengapa guru harus melakukan PTK. Pada saat itu disampaikan permasalahan-permasalahan yang mungkin akan timbul disekolah dan menjadi masalah bagi guru Pendidikan Agama Islam. Misalnya, tantangan motivasi siswa belajar, tantangan dekadensi moral dan akhlak yang semakin memperihatinkan dan masih banyak masalah yang lain berkaitan dengan siswa.

Untuk keperluan guru, PTK juga sangat penting, misalnya bagi 
guru yang berstatus pegawai negeri sipil terutama dalam rangka kenaikan pangkat. Begitu pula untuk institusi terutama dalam kelengkapan borang akreditasi yang harus disediakan adalah hasil PTK guru di sekolah tersebut. Maka tidak ada alasan lagi bagi guru untuk tidak melakukan PTK, karena PTK merupakan sesuatu yang urgen baik untuk institusi, guru dan siswa.

b) Meningkatkan kemampuan pengatahuan PTK

Benyamin Bloom mengatakan bahwa aspek-aspek dalam pendidikan meliputi aspek kognitif, afektif dan psikomotorik. Aspek psikomotorik tidak mungkin dapat dilakukan oleh seseorang yang belum mempunyai bekal pengetahuan kognitif dan afektif (Ahmadi, 1999) . Demikian juga PTK, seorang guru harus mempunyai pengetahuan yang cukup tentang ke-PTK-an sehingga mereka dapat meresapi dan dapat melakukan PTK dengan baik.

Pelatihan PTK ini juga memberikan bekal kepada para peserta tentang pengetahuan PTK yang disampaikan oleh Hanif
Cahyo Adi Kistoro tentang langkah-langkah PTK. Mulai dari bagaimana mengumpulkan masalah dan mengidentifikasi serta memutuskan masalah yang mana yang akan dilakukan PTK terlebih dahulu. Metode penelitian yang akan digunakan selama pelaksanaan PTK serta bagaimana menganalisisnya sampai bagaimana menyusun laporan PTK. Pada sesi ini juga diberi contoh-contoh PTK yang telah dilakukan oleh beberapa guru baik guru PAI maupun guru bidang studi umum.

Pada materi ketiga adalah cara penulisan literasi dengan menggunakan aplikasi Zotero yang disampaikan oleh Sutipyo Ru'iya, S.Ag., M.Si. Dan Materi keempat adalah sharing bagaimana cara meraih hibah PTK terutama hibah yang diberikan oleh Pimpinan Walayah Muhammadiyah Yogyakarta yang biasanya diberikan pada setiap tahun. Pada sesi ini pemateri memberikan kiatkiat dan contoh proposal yang telah lolos mendapat hibah PTK dari PWM pada tahun 2017. Materi disapaikan oleh Asih Suprapti, S.Pd.I. sebagai alumni Program 
Studi Pendidikan Agama Islam

UAD.

\section{PEMBAHASANAN}

Penyampaian materi ini dianggap sangat penting, dengan harapan para peserta dapat mengikuti langkahlangkah penulisan yang sesuai dengan gaya selingkung dari PTK yang diinginkan oleh PWM. Sesuai dengan harapan akhir dari pelatihan ini adalah seluruh peserta dapat melakukan PTK dan lebih-lebih dapat meraih hibah PTK dari unit-unit penyandang dana.

c) Meningkatkan keterampilan PTK

Keterampilan melakukan PTK merupaka tujuan akhir dari pelatihan ini, maka untuk mencapai target ini pada sesi Rencana Tindak Lanjut, diminta para peserta untuk menyusun proposal PTK yang akan dibahas pada pertemuan bulan berikutnya. Satu minggu sebelum pertemuan, seluruh peserta diminta untuk mengirim proposal yang akan diklinik pada pertemuan klinik proposal.

Tabel 4. Keberdayaan Mitra Kegiatan Ppm Reguler

\begin{tabular}{|c|c|c|}
\hline $\mathrm{No}$ & Jenis Mitra & Jenis Keberdayaan \\
\hline \multirow[t]{3}{*}{1} & \multirow{3}{*}{$\begin{array}{l}\text { Mitra Non } \\
\text { Produktif } \\
\text { Ekonomi }\end{array}$} & $\begin{array}{l}\text { 1. Pengetahuannya } \\
\text { meningkat }\end{array}$ \\
\hline & & $\begin{array}{l}\text { 2. Keterampilannya } \\
\text { meningkat }\end{array}$ \\
\hline & & $\begin{array}{l}\text { 3. Pelayanannya } \\
\text { meningkat }\end{array}$ \\
\hline
\end{tabular}

\section{KESIMPULAN DAN SARAN}

\section{KESIMPULAN}

Pengabdian Pada Masyarakat yang berjudul "Pelatihan Penelitian Tindakan Kelas bagi Guru Sekolah Menengah Pertama dan Madrasah Tsanawiyah Muhammadiyah se Kulon Progo" dapat dinyatakan berhasil dengan baik. Adapun indikator keberhasilannya adalah dari 29 peserta yang direncanakan hadir sebanyal 26 orang. Para peserta juga mengikuti pelatihan dari awal hingga akhir, sehingga mereka dapat dinyatakan mempunyai respon positif terhadap pelatihan ini.

Sebagai saran yaitu akan sangat bermanfaat jika unit-unit tertentu dari Pimpinan Wilayah Muhammadiyah lebih banyak memberi stimulasi agar para guru lebih semangat melakukan PTK.

\section{DAFTAR PUSTAKA}

Ahmadi (1999) Ilmu Pendidikan Islam. Yogyakarta: Aditya Media

Arikunto, S., Suhardjono, Supardi, (2009) Penelitian Tindakan Kelas. Jakarta: Bumi Aksara. 
Crowel, J. (2014) Penelitian Kualitatif, Kuantitatif, dan Campuran. Yogyakarta: Pustaka Pelajar

Hamalik, O. (2011) Proses Belajar Mengajar. Jakarta: Bumi Aksara.

Hamalik, O. (2014) Psikologi Belajar. Bandung: Remaja Rosda Karya.

Riyono, B. (2014) Motivasi dalam Pandangan Islam. Yogyakarta. Insan Cendekia

Sudijono, A. (2005) Pengantar Evaluasi Pendidikan. Jakarta: PT Raja Grafindo Persada.

Sudjana, N. (2011) Dasar-dasar Proses Belajar Mengajar. Bandung: Sinar Baru Algesindo

Suryosubroto, B. (2008) Proses Belajar Mengajar Di Sekolah. Jakarta: Rineka Cipta.

Susanto, E.B. (2012) PTK, Penelitian Tindakan Kelas Untuk Guru Dalam Rangka Menuju Pengembangan Profesi Berkelanjutan. Yogyakarta: Musahid Foundation.

Uno, H.B. (2011) Perencanaan Pengajaran. Jakarta: Bumi Aksara.

Uno, H.B. (2012) Motivasi. Jakarta: Bumi Aksara.

\section{Uno, H.B. (2012) Motivasi. Jakarta:}

Usman, M.U. (2002) Menjadi Guru Profesional. Bandung: PT. Remaja Rosda Karya. 